\title{
The effects of health education given by nurses to COPD patients on the daily oxygen concentrator usage time
}

The authors declare no financial disclosure

\section{Abstract}

Introduction: Long-term oxygen therapy is the most effective method which has been shown to prolong the lifespan in people with COPD. The aim of the study was to investigate the effects of health education given by nurses to patients with COPD on the daily oxygen concentrator (OC) usage time.

Material and methods: The study was carried out in a State Hospital, Turkey, between July and November 2015. After given consent to the study, participants were divided into intervention and control groups by simple random sampling method. Then data forms were filled during face-to-face interview. Firstly, the data describing patients' arrival times were collected retrospectively. Afterwards, the patients from the intervention group were educated through educational booklets prepared by the researchers. They were phoned in the weeks 4,8 and $12^{\text {th }}$ for problems they might have encountered during the use of OC. After the $14^{\text {th }}$ week, data forms of patients from the both groups were filled again; the results were compared with previous clinical findings. Data were analysed using SPSS 15.0 for Windows.

Results: It was determined that $95.5 \%$ of patients did not get information about the use of OC. Daily OC usage time (hour) by patients in the intervention group firstly amounted to $5.69 \pm 3.90$, later on to $11.94 \pm 4.73(p<0.05)$. Whereas when clinical findings concerning pre- and post educational periods were compared; a significant improvement in $\mathrm{PaO}_{2}, \mathrm{PaCO}_{2}, \mathrm{FEV}_{1}$ and $\mathrm{SaO}_{2}$ of patients in the intervention group $(p<0.05)$ was shown, contrary to the control group.

Conclusions: It may be recommended that patients receive continuous education and close monitoring of their results.

Key words: nursing, $\mathrm{COPD}$, health education, long-term oxygen therapy

Adv Respir Med 2017; 85: 15-21

\section{Introduction}

In these days, with increased early diagnosis and treatment options, the average life expectancy has begun to increase. But, this increase also brought along many chronic diseases. Chronic diseases are responsible for $63 \%$ of deaths occurring in 2008 [1]. Due to their burden, they affect both the individual and society [2]. Similarly, in our country, chronic diseases have become a major problem as a result of the aging of the population and the popularity of sedentary lifestyle [3].
According to data that the Turkish Statistical Institute investigated in 2014 the cause of $10.7 \%$ of deaths were respiratory diseases. Chronic obstructive pulmonary disease (COPD) is responsible for a significant part of these deaths [4]. According to data of the World Health Organization (WHO), COPD is the fourth most frequent cause of death in the world. On the report of the Ministry of Health of the Republic of Turkey on data for 2004, COPD was the third most frequent cause of death in the country [5]. It is known that COPD mortality and morbidity, both in our country and in the world, are constantly increasing [6]. 
Smoking or exposure to certain harmful gases are the most common causes of COPD. Unfortunately, the disease is progressive and never fully recovered. Cough, sputum production and dyspnoea are the most important symptoms of COPD. The patients who have these complaints can be diagnosed using several tests such as spirometry. Prevention of smoke exposure is one of the issues that need to be most carefully considered by diagnosed patients. There are pharmacological and non-pharmacological treatments provided to patients. As compared to others, long-term oxygen therapy (LTOT) is the most effective method which has been shown to prolong the lifespan in people with COPD. When the criteria for LTOT prescription in Turkey are examined, it seems that they are usually in accordance with the criteria of the American Thoracic Society (ATS) and European Respiratory Society (ERS) (proper arterial blood gas results, sufficient duration of therapy and non-smoking). When LTOT is used at home, among different oxygen supply options, oxygen concentrator (OC) belongs to the most commonly used devices. LTOT may be beneficial if it is applied at least 15 hours daily, including night time. It is also suggested that most of the COPD patients usually use low oxygen flow i.e. 1-2 L per minute. Studies have shown that most patients experience adaptation problems related to the use of OC. These problems significantly hamper the effective use of OC. The most frequent causes of non-compliance with OC are lack of awareness of the necessity of the therapy, cost of electricity consumption, noise of OC and ignorance of users [5, 7-11]. Accordingly, it could be said that patient education is an important factor in improving compliance with the oxygen treatment [12]. However, the literature about the issue turned out to be insufficient. Therefore, the present study has aimed to investigate the effects of health education given to COPD patients by nurses on the daily OC usage time. It is hoped that the study results will have some contribution to the literature on the issue.

\section{Material and methods}

\section{Designs}

This study was planned to be quasi-experimental.

\section{Setting and sample}

The study in the form of pre-test and posttest was conducted in the State Hospital of Chest Diseases Clinic and Policlinic, Turkey, between
July and November 2015. The minimum number of patients in each group was determined to be 11 persons. The inclusion criteria for the study were the following: diagnosis of COPD, command of the Turkish language, 18 years of age or older and patients who were prescribed oxygen concentrators in accordance with the criteria of ATS and ERS. Patients not meeting these criteria were excluded from the study. The participants were divided using simple random sampling method into two groups: intervention $(\mathrm{n}=32)$ and control $(\mathrm{n}=31)$ group.

\section{Data collection}

Study data were collected using a questionnaire form prepared by the researchers.

\section{Questionnaire form and educational booklet}

The questionnaire form and the educational booklet were prepared by the researchers basing on the relevant literature and the received expert opinion on the applicability [10,13-15]. The questionnaire form consisted of questions concerning the patients' demographic and clinical characteristics, OC usage practices and the level of satisfaction related to OC. The question form determining the level of satisfaction regarding OC consisted of seven questions, (yes/no answers). It was settled that "yes" answers are scored five and "no" answers are scored one. It was assumed that if the mean score increases, the level of satisfaction also increases.

The educational booklet including information related to COPD was given to patients. The booklet concerned the use of OC, misconceptions about OC, some suggestions on the problems encountered when using OC and solutions to them. The researchers' contact information was added to the final chapter so that patients could reach the authors in case of any problems.

\section{Procedure}

Data form was filled in face-to-face interview and some data for the arrival time of the patients in both groups such as $\mathrm{pH}, \mathrm{PaO}_{2}, \mathrm{PaCO}_{2}, \mathrm{FEV}_{1}$ and $\mathrm{SaO}_{2}$ were recorded. The data were obtained retrospectively from previous results of spirometry test and arterial blood gas analysis. The first results of arterial blood gas analysis were obtained during the exacerbation period. After the first interview, the patients from the control group were not phoned until the $14^{\text {th }}$ week.

In the first stage, the questionnaire was completed by the patients from both groups, and then topics in the education booklet were explained to patients from the intervention group. During 
Table 1. Analysis of personality traits of patients

\begin{tabular}{|c|c|c|c|c|c|c|c|c|}
\hline \multirow{2}{*}{$\begin{array}{l}\text { Characteristics } \\
\text { n }\end{array}$} & & \multicolumn{2}{|c|}{ Intervention group } & \multicolumn{2}{|c|}{ Control group } & \multicolumn{2}{|c|}{ Total } & \multirow[t]{2}{*}{$\mathbf{p}$} \\
\hline & & $\%$ & $\mathbf{n}$ & $\%$ & $\mathbf{n}$ & $\%$ & $\mathbf{n}$ & \\
\hline Number of Patients & & \multicolumn{2}{|c|}{32} & \multicolumn{2}{|c|}{31} & \multicolumn{2}{|c|}{63} & \\
\hline Age & & \multicolumn{2}{|c|}{$68.41 \pm 9.17$} & \multicolumn{2}{|c|}{$70.94 \pm 11.07$} & \multicolumn{2}{|c|}{$69.95 \pm 10.15$} & $0.329^{\mu}$ \\
\hline \multirow[t]{2}{*}{ Sex } & Male & 24 & 75 & 19 & 61.3 & 43 & 68.3 & $0.243^{\mathrm{a}}$ \\
\hline & Female & 8 & 25 & 12 & 38.7 & 20 & 31.7 & \\
\hline \multirow[t]{3}{*}{ Smoking status } & Yes & 4 & 12.5 & 6 & 19.4 & 10 & 15.9 & $0.099^{\mathrm{a}}$ \\
\hline & No & 8 & 25 & 14 & 45.2 & 22 & 34.9 & \\
\hline & Ex-smoker & 20 & 62.5 & 11 & 35.5 & 31 & 49.2 & \\
\hline \multirow[t]{2}{*}{ Comorbidity } & Yes & 23 & 71.9 & 13 & 41.9 & 36 & 57.1 & $0.016^{\mathrm{a}}$ \\
\hline & No & 9 & 28.1 & 18 & 58.1 & 27 & 42.9 & \\
\hline \multirow[t]{3}{*}{ Other diseases } & Cardiac & 4 & 17.4 & 1 & 7.7 & 5 & 13.9 & $0.087^{a}$ \\
\hline & Diabetes mellitus & 5 & 21.7 & 3 & 23.1 & 8 & 22.2 & \\
\hline & Others* & 14 & 60.9 & 9 & 69,2 & 23 & 63.9 & \\
\hline \multirow[t]{3}{*}{ Time of First diagnosis } & $0-5$ years & 10 & 31.2 & 5 & 16.1 & 15 & 23.8 & $0.151^{\mathrm{a}}$ \\
\hline & $6-10$ years & 6 & 18.8 & 12 & 38.7 & 18 & 28.6 & \\
\hline & 11 years and more & 16 & 50 & 14 & 45.2 & 30 & 47.6 & \\
\hline
\end{tabular}

the educational meeting, direct explanation and question-answer methods were used. In order for the education to be effective, it was provided that at least one of the patient's relatives could have attended the meeting and he or she was allowed to ask questions. At the end of the meeting, the educational booklet was given to the patients from the intervention group so that they could benefit therefrom. Then contact information of the patients was collected and they were phoned in the weeks 4,8 and $12^{\text {th }}$. Therefore, problems they had encountered during the usage of OC were solved and the most important rules were repeated. After the $14^{\text {th }}$ week, we wanted that the patients from the both groups consulted their doctors.

In the second stage, the questionnaire was completed by the patients from the both groups. The second results of arterial blood gas analysis were obtained in the non-exacerbation period. At the end of the study, the educational booklet was given to the patients from the control group.

\section{Ethics considerations}

Approval to conduct the study was given by the Gaziantep University Medical Ethics Committee (document number 2015/152) and Kilis State Hospital (document number 52446582/3736). The informed consent of patients participating in the study was also obtained. The patients were informed that they may leave the study at any time and personal information will be protected in accordance with the Declaration of Helsinki.

\section{Data analysis}

Data were analysed using SPSS 15.0 for Windows. Consequently, normality test was determined as having data consistent with normal distribution. The results were compared with previous clinical findings. Data were evaluated by Student t Test, Paired Sample t Test, One-Way ANOVA Test, Chi-square Test, percentage distributions and frequency. Statistically significant levels were set at $\mathrm{p}<0.05$.

\section{Results}

It was determined that $75 \%$ of the intervention group and $61.3 \%$ of the control group were males; the mean age of the intervention group was $68.41 \pm 9.17$, and of the control group $-70.94 \pm$ 11.07. $25 \%$ of patients in the intervention group and $45.2 \%$ of patients in the control group had never smoked. It was found that there was not statistically significant difference in terms of age, sex or smoking status of patients between the groups ( $\mathrm{p}>0.05)$ (Table 1). 


\section{Table 2. Comparison of the results of before and after education}

\begin{tabular}{|c|c|c|c|c|c|}
\hline \multirow{2}{*}{$\begin{array}{l}\text { Results } \\
\text { Means X } \pm \text { SD }\end{array}$} & & \multicolumn{2}{|c|}{ Intervention group ( $n=32$ ) } & \multicolumn{2}{|c|}{ Control group $(\mathrm{n}=\mathbf{3 1})$} \\
\hline & & $\mathbf{p}^{\infty}$ & $\begin{array}{c}\text { Means } \\
\bar{X} \pm \text { SD }\end{array}$ & $\mathbf{p}^{\infty}$ & \\
\hline \multirow[t]{2}{*}{$\mathrm{SaO}_{2}$} & Before & $82.06 \pm 3.97$ & 0.000 & $82.48 \pm 4.74$ & 0.133 \\
\hline & After & $85.91 \pm 4.44$ & & $81.03 \pm 5.35$ & \\
\hline \multirow[t]{2}{*}{$\mathrm{pH}$} & Before & $7.35 \pm 0.06$ & 0.222 & $7.36 \pm 0.04$ & 0.282 \\
\hline & After & $7.37 \pm 0.05$ & & $7.35 \pm 0.05$ & \\
\hline \multirow[t]{2}{*}{$\mathrm{PaO}_{2}$} & Before & $54.12 \pm 10.18$ & 0.003 & $55.49 \pm 7.17$ & 0.049 \\
\hline & After & $59.39 \pm 9.31$ & & $53.24 \pm 7.54$ & \\
\hline \multirow[t]{2}{*}{$\mathrm{PaCO}_{2}$} & Before & $46.92 \pm 9.32$ & 0.006 & $43.32 \pm 5.87$ & 0.174 \\
\hline & After & $43.39 \pm 5.29$ & & $44.75 \pm 8.22$ & \\
\hline \multirow[t]{2}{*}{$\mathrm{FEV}_{1}$} & Before & $38.88 \pm 10.16$ & 0.000 & $43.81 \pm 10.59$ & 0.398 \\
\hline & After & $44.16 \pm 10.25$ & & $42.84 \pm 10.38$ & \\
\hline \multirow[t]{2}{*}{ Level of satisfaction the related to $\mathrm{OC}$} & Before & $2.51 \pm 0.54$ & 0.000 & $2.37 \pm 0.3$ & 0.000 \\
\hline & After & $3.29 \pm 0.68$ & & $1.93 \pm 0.32$ & \\
\hline \multirow[t]{2}{*}{ The number of exacerbations in last three months } & Before & $6.69 \pm 3.17$ & 0.002 & $8.42 \pm 3.65$ & 0.008 \\
\hline & After & $5.19 \pm 2.15$ & & $6.77 \pm 2.02$ & \\
\hline \multirow[t]{2}{*}{ The number of hospitalizations in last three months } & Before & $3.13 \pm 1.43$ & 0.000 & $3.06 \pm 1.18$ & 0.693 \\
\hline & After & $1.94 \pm 1.31$ & & $2.97 \pm 1.54$ & \\
\hline \multirow[t]{2}{*}{ Daily OC usage time (hour) } & Before & $5.69 \pm 3.90$ & 0.000 & $3.77 \pm 1.33$ & 0.076 \\
\hline & After & $11.94 \pm 4.73$ & & $4.16 \pm 1.01$ & \\
\hline \multirow[t]{2}{*}{ Rate of $\mathrm{OC}$ flow meters (L/min) } & Before & $3.28 \pm 0.96$ & 0.033 & $3.32 \pm 0.83$ & 0.000 \\
\hline & After & $2.75 \pm 0.76$ & & $4.35 \pm 0.49$ & \\
\hline
\end{tabular}

${ }^{\infty}$ Paired samples T test

When the results obtained before and after the education provided were compared, it was revealed that some findings concerning the patients from the intervention group improved significantly e.g. $\mathrm{SaO}_{2}, \mathrm{PaO}_{2}, \mathrm{PaCO}_{2}, \mathrm{FEV}_{1}$, level of satisfaction related to OC, the number of exacerbations and hospitalizations during the last three months, daily OC usage time and rate of OC flow ( $p<0.05$ ). But, it was also found that the results of patients from the control group were not improved ( $p>0.05)$ (Table 2).

When the level of knowledge of the patients was investigated, it was found that $96.9 \%$ of the intervention group and $95.2 \%$ of the control group did not receive any information about the use of OC. When asked about the reason for not using OC, the patients stated that $63 \%$ of the intervention group and $51.6 \%$ of the control group did not have sufficient information about the use of OC $(p<0.05)$.

At the end of the study, some results were compared and it was shown that the patients who used OC on average for at least 15 hours daily had an adjusted rate of OC flow, i.e. $2.46 \pm$
$0.52(\mathrm{~L} / \mathrm{min})$, and some their results such as $\mathrm{SaO}_{2}$, $\mathrm{PaO}_{2}$ and the level of satisfaction related to OC improved, compared to the patients using OC less frequently $(\mathrm{p}<0.05)$ (Table 3$)$.

\section{Discussion}

At the end of the study there were $68.3 \%$ of males and $31.7 \%$ of females. In the research of Burden of Obstructive Lung Disease (BOLD) conducted by the Turkish Ministry of Health, it has been found that prevalence of COPD amounts to $28.5 \%$ in males and $10.3 \%$ in females [16]. When comparing our paper with the BOLD study, it is seen that the proportional difference between male-female sexes has decreased. It is known that men are at higher risk to get COPD than women because men more frequently smoke cigarettes and are more often exposed to certain harmful gases. However, it is estimated that this difference will gradually disappear as women are more sensitive to cigarette smoke and harmful gases [17]. 
Table 3. Comparison of some results after education according to daily $\mathrm{OC}$ usage time

\begin{tabular}{|c|c|c|c|c|}
\hline Results & Daily OC usage Time & n & Means $\bar{X} \pm$ SD & $\mathbf{p}^{\infty}$ \\
\hline \multirow[t]{2}{*}{ Rate of $\mathrm{OC}$ flow meter (L/min) } & $0-14$ hours & 50 & $3.82 \pm 0.94$ & 0.000 \\
\hline & 15 hours and more & 13 & $2.46 \pm 0.52$ & \\
\hline \multirow[t]{2}{*}{ The number of exacerbations in last three months } & $0-14$ hours & 50 & $6.2 \pm 2.16$ & 0.105 \\
\hline & 15 hours and more & 13 & $5.08 \pm 2.29$ & \\
\hline \multirow[t]{2}{*}{ The number of hospitalizations in last three months } & $0-14$ hours & 50 & $2.52 \pm 1.54$ & 0.441 \\
\hline & 15 hours and more & 13 & $2.15 \pm 1.4$ & \\
\hline \multirow[t]{2}{*}{$\mathrm{SaO}_{2}$} & $0-14$ hours & 50 & $82.7 \pm 5.39$ & 0.020 \\
\hline & 15 hours and more & 13 & $86.62 \pm 4.62$ & \\
\hline \multirow[t]{2}{*}{$\mathrm{pH}$} & $0-14$ hours & 50 & $7.35 \pm 0.05$ & 0.102 \\
\hline & 15 hours and more & 13 & $7.38 \pm 0.04$ & \\
\hline \multirow[t]{2}{*}{$\mathrm{PaO}_{2}$} & $0-14$ hours & 50 & $55.1 \pm 8.86$ & 0.027 \\
\hline & 15 hours and more & 13 & $61.22 \pm 7.92$ & \\
\hline \multirow[t]{2}{*}{$\mathrm{PaCO}_{2}$} & $0-14$ hours & 50 & $44.09 \pm 7.08$ & 0.951 \\
\hline & 15 hours and more & 13 & $43.95 \pm 6.27$ & \\
\hline \multirow[t]{2}{*}{$\mathrm{FEV}_{1}$} & $0-14$ hours & 50 & $43.6 \pm 10.85$ & 0.890 \\
\hline & 15 hours and more & 13 & $43.15 \pm 7.86$ & \\
\hline \multirow[t]{2}{*}{ Level of satisfaction the related to $\mathrm{OC}$} & $0-14$ hours & 50 & $2.31 \pm 0.7$ & 0.000 \\
\hline & 15 hours and more & 13 & $3.79 \pm 0.14$ & \\
\hline
\end{tabular}

${ }^{\infty}$ One-Way ANOVA Test

When the results obtained before and after the education provided were compared, it was discovered that some parameters concerning the patients from the intervention group significantly improved, e.g. $\mathrm{SaO}_{2}, \mathrm{PaO}_{2}, \mathrm{PaCO}_{2}, \mathrm{FEV}_{1}$, level of satisfaction related to OC, the number of exacerbations and hospitalizations during the last three months, daily OC usage time and rate of OC flow. On the contrary, the relevant findings on the patients from the control group got worse. In the study conducted by Duzenli et al. [18], it has been reported that in some blood gas values and $\mathrm{FEV}_{1}$ of patients who regularly used oxygen, improvement was observed. The present study has also reported that patients who regularly used oxygen had a smaller number of hospitalizations than those not using OC on a regular basis. Furthermore, some blood gas values and results of spirometry test of the patients who were not using LTOT, did worsen [18]. When the intervention group was compared with the control group, significant differences in many parameters indicating the severity of the disease were found. They included the results of spirometry test, arterial blood gas values and the number of exacerbations and hospitalizations. During the present study, it was aimed to increase the daily OC usage time in the intervention group. Finally, the time of use of
OC by the patients from the intervention group increased to $11.94 \pm 4.73$ hours daily. This value is below the advised rate in the literature, which is at least 15 hours daily. However, it is considered that if OC is used regularly, clinic parameters of the patient may improve.

During the examination of the level of knowledge about the use of OC, it was seen that most of patients previously received no information about the issue. In the study conducted by Turker et al. [13], the authors have reported that sufficient information about treatment and the usage of OC was not given to patients who were prescribed OC. More than half of patients not using OC regularly stated that they had not been informed about the use of OC. It is known that most common situations preventing the use of OC are caused by lack of knowledge [19, 20]. We believed that patients suffered from problems related to the use of OC because of insufficient information.

In the post-education period, the patients were examined according to daily OC usage time. It was determined that the patients who used OC on average for at least 15 hours daily have had an adjusted rate of OC flow, i.e. $2.46 \pm 0.52$ (L/ min), and some their results such as $\mathrm{SaO}_{2}, \mathrm{PaO}_{2}$ and level of satisfaction related to $\mathrm{OC}$ were better than those in other patients. In a similar study 
conducted by Nasilowski et al. [12], it has been reported that $\mathrm{FEV}_{1}$ and $\mathrm{PaCO}_{2}$ values of patients who used OC on average for at least 15 hours daily, are better than the relevant parameters of individuals using OC less frequently. In the study conducted by Karamanlı et al. [21], it has been also reported that cognitive status of COPD patients who use regularly OC is better than in those using the device irregularly [21]. At the end of our study, it was determined that if daily OC usage time is increased, clinic parameters of patients may improve.

\section{Conclusions}

It has been known that oxygen treatment is both an important treatment method in COPD and the factor increasing the lifespan of patients. The study results have shown that the daily OC usage time by patients increased after a specific education programme. Additionally, their other health parameters improved, e.g. level of satisfaction related to OC, the number of exacerbations and hospitalizations during the last three months, some blood gas values and results of spirometry test. It is our belief that this improvement can reduce the number of hospitalizations and healthcare costs. Moreover, it may be recommended that patients receive continuous education and close monitoring of their results.

Nowadays, it is believed that the patient education is one of the most important components of COPD treatment. But, our study has shown that almost all of the subjects had not received enough information related to COPD and its treatment. Insufficient information causes non-compliance with treatment process because it prevents the expected benefits of treatment. Consequently, this situation can cause an increase in the number of hospitalizations and healthcare costs. The brightest point of the study is that the results of the educational programme given by the nurses are monitored. Both information level and patients'compliance with treatment may increase thanks to education given by nurses who spend the most time with patients. Nevertheless, we believe that nurses are informed about the need for patient education because proper education can be given by prepared personnel. We think that results of education programmes can be generalised by forming more extensive research groups.

\section{Limitations}

This study was conducted using a limited sample group. The results may not be applicable to other segments of the population in Turkey or other countries. Moreover, information related to the use of OC depended on the patients' statements so it could have not been evaluated objectively.

\section{Acknowledgements}

The research received no specific grant from any funding agency in the public, commercial or not-for-profit sectors.

The paper was orally presented at the $3^{\text {rd }}$ International Eastern Mediterranean Nursing Congress (2016).

\section{Conflict of interest}

The authors declare no conflict of interest.

\section{References:}

1. World Health Organization. Global status report on noncommunicable diseases 2010. Published 2011. www.who.int/nmh/ publications/ncd_report_full_en.pdf; 11.04.2016.

2. Strong K, Mathers C, Leeder S, et al. Preventing chronic diseases: how many lives can we save? Lancet. 2005; 366(9496): 1578-1582, doi: 10.1016/S0140-6736(05)67341-2, indexed in Pubmed: 16257345.

3. Republic of Turkey Ministry of Health. National burden of disease and cost effectiveness project 2004. www.toraks.org. tr/userfiles/file/ulusal_hastalik_yuku_hastalikyukuTR.pdf; 2.05.2016.

4. Turkey Statistical Institute. Cause of death statistics 2014 www.tuik.gov.tr/PreHaberBultenleri.do?id=18855; 19.04.2016.

5. Turkish Thoracic Society. Consensus report of diagnosis and treatment for COPD. www.toraks.org.tr/Download.aspx?bo$\mathrm{ok}=43 ; 31.01 .2016$.

6. Aras A, Tel H. Determination of Perceived Social Support for Patients with COPD and Related Factors. Tur Toraks Der. 2009; 10: $63-68$

7. Hardinge M, Annandale J, Bourne S, et al. British Thoracic Society Home Oxygen Guideline Development Group, British Thoracic Society Standards of Care Committee. British Thoracic Society guidelines for home oxygen use in adults. Thorax 2015; 70 Suppl 1: i1-43, doi: 10.1136/thoraxjnl-2015-206865, indexed in Pubmed: 25870317.

8. Meena M, Dixit R, Kewlani JP, et al. Home-based long-term oxygen therapy and oxygen conservation devices: An updated review. Natl J Physiol Pharm Pharmacol. 2015; 5(4): 267, doi: 10.5455/njppp.2015.5.0912201429.

9. O'Reilly P, Bailey W. Long-term continuous oxygen treatment in chronic obstructive pulmonary disease: proper use, benefits and unresolved issues. Curr Opin Pulm Med. 2007; 13(2): 120-124, doi: 10.1097/MCP.0b013e32802c7cfe, indexed in Pubmed: 17255802.

10. Tutluoğlu B, Atış S, Özge C, Salepçi B, Yılmazkaya Y. Longterm oxygen therapy at home in chronic obstructive pulmonary disease. Respiratory Diseases. 2000; 11: 338-342.

11. Pekçalışkan Ku, Uçan ES, Şahbaz S, et al. Efficiency of long term oxygen therapy and patients therapy compliance. Turkish Thoracic Journal. 2007; 8(3): 163-169.

12. Nasiłowski J, Przybyłowski T, Klimiuk J, et al. [Effects of nurse home visits on compliance to long-term oxygen therapy. 14 months follow-up]. Pneumonol Alergol Pol. 2009; 77(4): 363-370, doi: 10.4172/2165-8048.1000143, indexed in Pubmed: 19722141.

13. Türker G, Kızkın Ö, Hacıevliyagil SS, et al. The pitfalls in the prescription and usage of oxygen concentrators. Respiratory Diseases Journal. 2002; 13: 7-11. 
14. Czajkowska-Malinowska M, Połtyn B, Ciesielska A, et al. [Comparison of the results of long term oxygen therapy in patients treated sequentially using stationary or a portable source of oxygen]. Pneumonol Alergol Pol. 2012; 80(4): 308-316, indexed in Pubmed: 22714074.

15. Akçay Ş, Öner Eyüboğlu F, Çelik N, Aydın G. Compliance with long-term oxygen therapy in patients with chronic respiratory failure and related factors. Tuberculosis and Thorax. 2001; 49 (1): 13-20.

16. Kocabaş A. Chronic obstructive pulmonary disease epidemiology and risk factors. Bulletin of Thoracic Surgery. 2010; 1, 2: 105-113.

17. Hylkema MN, Sterk PJ, de Boer WI, et al. Tobacco use in relation to COPD and asthma. Eur Respir J. 2007; 29(3): 438445, doi: 10.1183/09031936.00124506, indexed in Pubmed: 17329490.
18. Düzenli H, Doğan OT, Berk S, et al. [The effects of long-term oxygen therapy on survey in patients with chronic respiratory failure]. Tuberk Toraks. 2008; 56(2): 179-186, doi: 10.1136/ thx.51.2.228-b, indexed in Pubmed: 18701978.

19. Tanrıverdi E, Hasanoğlu H C. Reliability of long cannula usage in patients under home oxygen therapy with concentrator. Medical Journal of Göztepe. 2013; 28(4): 186-193.

20. Díaz Lobato S, García González J L, Mayoralas Alises S. Controversias en oxigenoterapia continua domiciliaria. Arch Bronconeumol. 2015; 51: 31-37.

21. Karamanli H, Ilik F, Kayhan F, et al. Assessment of cognitive impairment in long-term oxygen therapy-dependent COPD patients. Int J Chron Obstruct Pulmon Dis. 2015; 10 2087-2094, doi: 10.2147/COPD.S88326, indexed in Pubmed: $\underline{26491279}$ 